\title{
Yo estuve allí...
}

Sí, yo estuve allí. Nadie me lo ha contado. Lo he visto con mis propios ojos y lo he oído, como decía aquél, con mis castas orejas. Yo estuve allí el 19 de mayo de 1967, "en la pequeña fiesta que hoy después de cena -así se lee en el Diario para esa fecha- han organizado los de la Provincia para celebrar la afiliación de Valladolid a Comillas -(ya se sabe a qué se refería)- y que ha resultado lo que siempre en tales ocasiones. Una juventud que se siente con poderes de crítica, aunque le falten los elementos esenciales para emitir un juicio. Se entabló -prosigue el Diario- discusión sobre las clases y una vez más se confunden los términos: se reduce la teología a una pura especulación, sin percatarse de que sus criterios lo son de la Escritura, la tradición y los concilios. A la larga se dejan notar muchas cosas, y entre otras el miedo que tienen a que alguien les diga la verdad a la cara. No obstante, a pesar de mi temor por ellos continuaré reclamándoles el orden y piensen lo que les plazca, intentaré clarear sus horizontes de comodidad". Unos meses antes, el 9 de febrero de 1967 se leía una nota al final: "Ha llegado Paciano con la 'Pro-Memoria' para la agregación de Valladolid a Comillas".

Quizá ni los términos estaban muy claros ni los tenía claros tampoco la institución a que se dirigía, pero sí había claro un objetivo: que el Seminario Mayor Agustiniano de Valladolid se convirtiera en un auténtico Estudio Teológico Agustiniano y que fuera su rango de nivel superior, que cuanto ya ostentaba de hecho en sus prestagiados profesores y en sus alumnos, lo revelara y lo mostrata también en la posibilidad de titulación.

Yo estuve allí, sí, y allí apareció una hoja, de puño y letra, que llevaba por título "ABAJO LAS MÁSCARAS” y que pretendía convertirse en libro, aunque luego fue sólo unas conferencias cuyo rastro se ha perdido. Pero sí me interesa recoger aquí aquel breve esquema:

Prólogo: -Hipocresía, farsa, medias tintas, miedos a una formación completa, humana, cristiana y religiosa. -Desilusión, desencanto, insatisfacción y deserción consiguiente. -Valorar lo positivo y fundamentar.

I. Cosas, no personas: Todo cosificado, dan cosas o prestan servicios, no entrega de la persona, se tiene miedo. -Las leyes con cosas y sobre ellas...

II. Evadirse no, arriesgarse. 
III. Lo corporal no, el cuerpo (abajo borrado, lo carnal no, la carne).

IV. Sí a la sensibilidad.

V. Sí al amor

VI. Sí a la libertad

VII. Sí a la razón

VIII. Sí a lo cristiano

IX. Sí a lo religioso

X. Gracias, soy persona.

Conclusión: Ésta era la ganancia y lo que quería el Concilio. Citar por ahí.

¿Habría otro modo? ¿Se podría vivir mejor y habría métodos distintos para llegar a la profundidad del ser humano? ¿Era necesario continuar con los mismos contenidos y echar vino nuevo en odres viejos? ¿El Concilio no quería otra cosa? ¿No había dicho Pablo VI, el 7 de diciembre de 1965, que "la antigua historia del samaritano ha sido el paradigma de la espiritualidad del Concilio?”. ¿No se nos había pedido una "metanoia", un cambio de mentalidad y que fuera en vertical y en horizontal? ¿No se nos abrió el camino y ése era precisamente el Cristo-vía y era vía en cuanto "homo"? ¿Se necesitaba más método y mejor? Y entonces ¿por qué se volvía la vista atrás y se apelaba de nuevo al "Theos" y no al "Custos"?

¿No se nos dijo: "Somos testigos de que nace un nuevo humanismo, en el que el hombre queda definido principalmente por su responsabilidad hacia sus hermanos y hacia la historia (GS. n.55)?”. ¿Acaso en la clausura del Concilio Vaticano II no no resumió PabloVI toda la tarea en aquellas palabras: " $Y$ si recordamos cómo en el rostro de cada hombre, especialmente si se ha hecho transparente por sus lágrimas y por sus dolores, podemos y debemos reconocer el rostro del Cristo (cf. Mt 25,40), el Hijo del hombre, y si en el rostro de Cristo podemos y debemos además renococer el rostro del Padre celestial: Quien me ve a mí -dijo Jesús-ve también al Padre (Jo. 14,9), nuestro humanismo se hace cristianismo, nuestro cristianismo se hace teocéntrico, tanto que podemos afirmar también que para conocer a Dios es necesario conocer al hombre?". He aquí el programa.

Aún hoy me duele el Concilio, porqu lo viví en propia carne y su última expresión parecía el mejor principio de todo un nuevo pensamiento, que era antiguo, y de una mentalidad que estaba ya en la más arraigada y profunda vena agustiniana. “ ¿Estaría entonces destinado este Concilio -añadía el Papa Pablo VI-, que ha dedicado al hombre principalmente su estudiosa atención, a proponer de nuevo al mundo moderno la escala de las liberadoras y consoladoras ascensiones? ¿No sería, en definitiva, un simple, nuevo y solemne 
enseñar a amar al hombre para amar a Dios?”. ¿No se convierte en "una potente y amistosa invitación a la humanidad de hoy a enconctrar de nuevo, por la vía del amor fraterno, a aquel Dios, 'de quien alejarse es caer, a quien dirigirse es levantarse, en quien permanecer es estar firmes, a quien volver es renacer, en quien habitar es vivir'?"' (S. Agustín, Solil. I, 1,3 PL 32,870).

El Concilio fue, pues "un solemne acto de amor a la humanidad", y Pablo VI concluirá, con un grito de alegría, que "hemos aprendido a amar más y a servir mejor a la humanidad", que hemos "aprendido a amar al hombre de hoy tal cual es" (PABLO VI, Aloc. 7-XII-1965, BAC, 819; cf. José MORÁN, El hombre y los valores humanos en el concilio Vaticano II, en Archivo Teológico Agustiniano, I,1-2(1966), pp. 87-114). ¿No suena bien en nuestros oídos y en nuestra vida esta melodía de amor? y ¿no duele todavía hoy a muchos esa resonancia avasalladora?

Sí, yo estuve allí y aún me siguen doliendo esas palabras, porque las leo diariamente en mi dulce caminar por la senda de San Agustín. Y estuve allí el 22 de mayo de 2008 en el Acto Conmemorativo del XL Aniversario de la fundación del Estudio Teológico Agustiniano de Valladolid. Y estaban todos, o casi todos, aunque ya muchos descansan tras la batalla en la paz del Señor, augurando desde la otra orilla, que encontremos -o encuentren- el camino para que sus pasos no conduzcan a ninguna parte, y otros no han podido sonreír al acto. Había cambiado todo el exterior, se "había adaptado a los tiempos" la estructura y se seguía adaptando, se "aggiornaron" las vestimentas, se apreciaban las diferencias, siempre necesarias, con "collar" unos, los más conspicuos, con corbata otros, de acuerdo a rangos y con traje entrecortado quienes, para no distinguir, se mezclan.

Y hablaron todos los que ocupaban la mesa presidencial. Sería largo expresar el contenido. Sí sabemos que lo hizo el Director del Estudio Teológico Agustiniano, quien apeló al número cuarenta en la Biblia para fundamentar y engarzar la celebración de los XL Años, pero a los cuarenta, comentaría Agustín de Hipona a veces, le faltan diez para cincuenta y esos diez serían los diez mandamientos y éstos se reducen al final a dos, en los que se incluye un tercero: Dios, el prójimo y tú o yo mismo, como quieras. Tal vez fuera el camino y acudió a la historia, pero en breve, porque habría alguien que la explicitaría mucho más.

Augurio y bienvenida a la Teología, cediendo la palabra al Decano de la Facultad de Teología de la Universidad de Comillas, quien implicó la teología y sus métodos en círculos concéntricos en torno a las Constituciones y Decretos del Concilio Vaticano II, yendo a parar sea en cristología, sea en la eclesiología, con apertura global y ecuménica con sus Decretos correspondientes, tan mimado como es hoy el diálgo intercultural o el diálogo 
interreligioso. Pueden ser muchos los círculos, pero la elección es de cada Facultad o de cada Universidad, o diría más, casi de cada profesor, manteniendo la línea en la que se desenvuelva. Porque, a continuación, el Decano de la Facultad de Teología del Norte de España, sede Burgos, apeló a esa misma teología, tambien para hoy y también post-conciliar, según ellos mismos y recurrió a Dios no como objeto, sino como sujeto de la teología, ampliando el tema en un horizonte de "noche oscura del alma", donde la fe se hace presente para iluminar el sendero, en el que de Dios se puede decir todo y nada digno se puede decir de Él, o abocándose a una teología negativa, diciendo de Dios qué no es más bien que qué es, o a una teología apofáxica, quedándose sin palabras...

La palabra se alargaba en la historia del Estudio Teológico Agustiniano con el Presidente del Patronato, recordando, sobre todo, el espíritu misionero y la formación para la misión y las misiones, y se diluía, entrecruzada, en boca del General de los Agustinos, se hacía miel en los labios del Arzobispo de Valladolid y cerraba en "lo mejor aún queda por venir" del Arzobispo de Burgos y Gran Canciller de la Facultad de Teología del Norte de España, sede Burgos, clausurando con la anécdota las intervenciones y finalizando con "lo mejor queda aún por venir". El coro Picolo pondría sus limpias, pulcras y melodiosas voces al servicio de canciones clásicas y modernas, todas con una exquisita referencia a cuanto se estaba celebrando.

Y en el aire vibraba una pregunta, en los rostros asomaba un misterio, mientras las manos se movían para aplaudir. ¿Los teólogos habían llegado al público? Sus disquisiciones, sus "círculos concéntricos", o su "Dios como sujeto, no como objeto", tenían algun significado para los oyentes? ¿Les interesaba realmente el hombre, o si se me permite ir más allá, siquiera el cristiano? ¿Habían entendido algo de lo que habían escrito para comunicarles? Pero además, ¿les interesaba realmente que lo entendieran? ¿No era equívoco al menos el camino tomado -la vía-? ¿No decían ellos que seguían el Concilio Vaticano II y que acudían a esa fuente? ¿No habría que cambiar el signo y el ritmo? ¿No era otro el camino, el método, la vía?¿Por dónde nos guía el Maestro hacia la Verdad?¿No es acaso a través de la humanidad, en la que se ha escondido la divinidad? ¿No es acaso "via” por "homo"? ¿No fue Pilatos el primer teólogo -y "¿qué es la verdad?”- y no se dio él mismo la respuesta para mostrársela al pueblo: "Ecce homo", "He ahí el hombre”. Y ¿cómo estaba el hombre? Azotado, abofeteado, coronado de espinas, ensangrentado, "no había por donde cogerlo", decía aquella señora cuando le preguntaron. "He ahí el hombre": llevad el hombre al extremo, situadlo ante el abismo, mostradle el precipicio, descubridle lo que es y lo que 
busca, entregádselo todo y en su borrachera total interrogadle: ¿Eres feliz? ¿Es ésa la verdad?

Creed en y a ese hombre, amad a ese hombre y esperad que crezca en la fe y en el amor, porque ya la vida es un acto de fe, porque tenemos que amar para vivir, porque la esperanza es plaza fuerte con la fe y el amor. ¿No recuerdas la constitución "pística, filíaca y elpídica de la persona humana?".

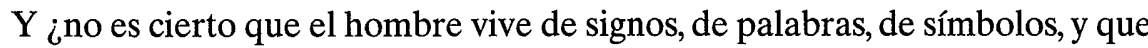
sus signos verbales y no verbales, sensibles, se convierten en puentes de lo visible a lo invisible? $\mathrm{Y}$ ¿qué son los sacramentos?

¿Acaso no es el amor la medida de la fe y no es la inteligencia emocional, hoy tan de moda, producto y fruto maduro del amor? ¿No se nos ha dicho que conoceremos a Dios en el amor del hermano y que el amor fraterno es la clave para ver y entender a Dios? ¿No habrá entonces que cambiar el camino, el "método", para hacer que el hombre busque a Dios desde el amor a los hombres, sus hermanos? ¿No es cierto que al final no se nos preguntará qué creímos o en qué creímos, sino qué amamos o qué hicimos con el amor, ya que únicamente prevalecerá o subsistirá el amor?

¿Qué triste ¿no?! En teología se nos ha hablado -y se nos habla aún- de todo, menos del amor. Y sólo por él y por su medio puede entenderse la fe, que no es en una cosa ni siquiera en una verdad, o en "verdades", son una persona y cuyo contenido se derrama en el misterio de esa misma persona. $\mathrm{Y}$ al santuario de la persona se ingresa por el camino del amor y sólo por el y con él, amando y siendo amado, se crea la telaraña de la relación interpersonal, que es "comunión", "yo y tú", que es "ecclesia”, persona total"Cristo total", que se ama a sí mismo". Y en la persona cuando un miembro se duele, le duele a todos los demás y todos a una gritan, a través de uno de ellos, para que desaparezca el dolor, pero juntos, siempre juntos, no separados. ¿No debe suceder igual en la sociedad, cuando ésta es una "sociedad de amor", una "compago unitatis?" Quizás los términos suenan hoy de otra manera, y sea la solidaridad la palabra adecuada, pero ésta carece de sentido, si falta el aglutinante, que es el amor.

Mas Dios es amor y solamente a través del amor podemos conocerlo a Él. Todos los caminos están abiertos a quien ama y ahí aprendemos que "quien ama, no sufre y si sufre, ama el mismo sufrimiento" y ahí conocemos que "cantar es oficio de amantes o de quien ama" y que la alegría es la hija legítima del amor, con cuanto ello comporta. Y además aprendemos que, amando al hermano, o porque ya lo es o para lo sea, descubrimos el secreto de Dios que es amor, pudienco fácilmente apreciar aquel "ama y haz lo que quieras" y "ama y di lo que quieras". San Agustín sonríe y nos mira agradecido: Volved vuestra mirada al interior y descubrid que Dios es amor 
y que quien ama, ama por amor, y que ese amor es Dios, y sólo a través del amor y amando conoces y conocerás a quien lo es. Y entonces entiende uno que la globalización entra en la mirada ecuménica del amor.

He revisado la Guía Académica y he enfrentado muchas Guías Académicas y he constatado que en filosofía se habla de emociones y sentimientos, de persona y de personalidad y de temas afines y más profundos en psicología, pero en teología hay revelación, hay Escritura, hay moral y hay los temas de siempre, abordados con la mirada fija en determinadas historias. Faltan las vivencias, los hechos -facta, non lingua; cor non verba-, el corazón, eso que todos los días se vive y que suele ingresar en los volúmenes de las inteligencias privilegiadas. Y la esencia del cristianismo, el amor, brilla por su ausencia y iqué difícil es conocer a Dios, partiendo de Dios a quien no conocemos! Me dirá usted: No hable de amor, hable de "caridad" o de "dilectio", y Agustín nos diría que también Jesús le dijo a Pedro: "Pedro, ¿me amas?" (Amas me, no, Diligis me?, y además que "tempora habent verba opportuna".

Enfrascados en discusiones estériles, olvidamos con frecuencia que Dios es amor y que sólo el amor nos permite conocerlo, que es necesario llegar al conocimiento de Dios por medio del amor a nuestros hermanos, los hombres. Y ¿qué es el amor? "Mi amor es mi peso, por él soy llevado doquiera vaya”. ¿Lo recuerdas? Tú ya lo sabes. Yo estuve allí, pero hoy estoy aquí para decirte que mires la teología como una "teofilía", no como "amor de Dios", sino como "Dios es amor”. Todo cambiará. ¡Hasta las verdades se harán amorosas! Prueba y verás. 